\title{
The Remedial Value of Blushing in the Context of Transgressions and Mishaps
}

\author{
Corine Dijk and Peter J. de Jong \\ University of Groningen
}

\author{
Madelon L. Peters \\ Maastricht University
}

\begin{abstract}
This study investigated the remedial value of blushing in the context of clear-cut predicaments. Besides testing the effects of displaying a blush on a neutral expression, we investigated whether blushing increased the remedial properties of shameful and embarrassed expressions. After reading a vignette describing either a transgression (Experiment $1 ; N=66$ ) or a mishap (Experiment $2 ; N=62$ ), participants saw pictures of people with or without a blush and rated them on several dimensions (e.g., sympathy, trustworthiness). The results of both experiments supported the hypothesis that blushing has remedial properties. In most instances, blushing actors were evaluated more favorably than their nonblushing counterparts. Although people often consider blushing to be an undesirable response, our results showed that, in the context of transgressions and mishaps, blushing is a helpful bodily signal with face-saving properties.
\end{abstract}

Keywords: blushing, appeasement, nonverbal communication, embarrassment, shame

Blushing is a puzzling phenomenon. Although the physiology of the response is known to some extent (e.g., Drummond \& Lance, 1987; Mellander, Andersson, Afzelius, \& Hellstrand, 1982), what precisely causes the facial veins to dilate from time to time remains largely unclear (see Crozier, 2006, for an extensive review about blushing). Nevertheless, it appears that blushing is a salient response in interpersonal situations that involve self-consciousness (Crozier, 2006; Darwin, 1872/1989), such as being caught performing a mishap or a social transgression. Accordingly, the blush often appears together with the self-conscious emotions that arise in these kinds of situations, such as embarrassment and shame (e.g., Buss, 1980; Castelfranchi \& Poggi, 1990; Shields, Mallory, \& Simon, 1990).

Several theorists have stressed the functional properties of expressing embarrassment and shame (e.g., Castelfranchi \& Poggi, 1990; Keltner, 1995), and have argued that these expressions may help restore the actor's public image after a mishap or transgression (cf. Frijda, 1986). That is, publicly conveying embarrassment or shame may signify the actor's recognition that she/he has committed a social or moral infraction, and regrets this (cf. Semin $\&$ Manstead, 1982). As a consequence, this message may mitigate the negative social impression that was caused by the infraction

Corine Dijk and Peter J. de Jong, Department of Clinical and Developmental Psychology, University of Groningen; Madelon L. Peters, Department of Medical, Clinical, \& Experimental Psychology, Maastricht University.

Corine Dijk was supported by a fellowship from the Netherlands Organization for Scientific Research (Grant 016.005.019). We are grateful to Sanne Hooghuis, Gemma Kok, Karina Meininger, Iris Rooke, and Nienke Straatman for their help with conducting the pilot study, and to Nico Frijda for his helpful comments on a previous version of this article.

Correspondence concerning this article should be addressed to Corine Dijk, Roetersstraat 15, 1018 WB, Amsterdam, the Netherlands. E-mail: k.f.l.dijk@uva.nl
(Keltner, Young, \& Buswell, 1997). Accordingly, it has been argued that blushing has appeasement-related properties similar to those of self-conscious emotions (e.g., Castelfranchi \& Poggi, 1990; Cutlip \& Leary, 1993). In line with these putative signaling properties of the blush, there is tentative evidence indicating that blushing can indeed positively influence observers' judgments. A series of vignette studies showed that when participants were asked to imagine that actors had committed seemingly involuntary mishaps or voluntary transgressions, imagining that these actors blushed attenuated their negative impression (de Jong, 1999; de Jong, Peters, \& De Cremer, 2003).

However, whether blushing indeed has signal value when it is displayed simultaneously with self-conscious emotions cannot be reliably deduced from the available evidence. That is, vignette studies that were designed to test the effect of blushing on observers' judgments in the context of mishaps and transgressions did not isolate the blush from the other features of an appeasement display. It seems very likely that the participants in these experiments did not just imagine a sole reddening of the face, but a complete emotional display including a blush. Likewise, it is obvious that studies that tested the interpersonal effects of blushing in the context of real interactions (e.g., de Jong, Peters, De Cremer, \& Vranken, 2002), were unable to isolate the blush from other concomitant (facial) expressions. Therefore, the present study was designed as a more direct test of the hypothesis that in itself, blushing has remedial properties. In addition, we explored the effect of blushing on top of other facial expressions of selfconscious emotions. If blushing is indeed an important part of the appeasement display, it should increase the remedial value of other expressions associated with shame and embarrassment.

Shame and embarrassment are distinct emotions (e.g., Babcock \& Sabini, 1990; Keltner, 1995; Keltner \& Buswell, 1996; Miller \& Tangney, 1994; Tangney, Miller, Flicker, \& Barlow, 1996). Shame is associated with more global and enduring negative attributions about oneself, whereas embarrassment is tied to more transient, 
situation specific, failures and pratfalls for which less responsibility is felt (Tangney et al., 1996). The antecedents of embarrassment are mishaps such as a loss of bodily control or cognitive shortcomings (Keltner \& Buswell, 1996; Modigliani, 1968). Shame follows from more severe transgressions such as hurting others emotionally or shortcomings in moral worth (Babcock \& Sabini, 1990; Keltner \& Buswell, 1996). Because expressing shame or embarrassment is appropriate in different types of situations, we investigated the remedial properties of blushing in situations that usually elicit shame (transgressions; Experiment 1) and situations that tend to elicit embarrassment (mishaps; Experiment 2) separately.

We tested the following predictions. First, if blushing indeed has remedial properties, then even if the model's facial expression is neutral, she will be judged more favorably when she displays a blush than when she does not display a blush. Second, if blushing is an important feature of the appeasement display, it will increase the remedial properties of other concomitant expressions of shame and embarrassment.

\section{Method}

\section{Participants}

There were 66 participants in the transgression experiment (45 female, 21 male) and 62 participants in the mishap experiment (35 female, 27 male). All participants were students from the University of Groningen who cooperated for course credits or, if they did not need these credits, received 5 euros. The participants' gender did not influence any of the results and will therefore not be discussed any further.

\section{Materials}

Photographs. The color photographs consisted of the head and upper chest of 24 women. The models displayed shame (a head movement and gaze downward); embarrassment (a non-Duchenne smile [in which there is no activation of the m.orbicularis oculi], lip press, gaze downward, face touching and a head movement slightly downward); or a neutral face (which consisted of a relaxed look, straightforward; see Keltner, 1995; Keltner \& Buwell, 1996). All models were White and between the ages of 19 and 30. The photographs of these 24 models were manipulated with the program Corel Paint Shop Pro 7 to color them with a lifelike blush. To examine to what extent the person in the picture displayed embarrassment or shame, we let the participants rate the photographs again after the experiments. The result showed that for both experiments the neutral expression was indeed seen as far less emotional (both $p \mathrm{~s} \leq .001$ ). Furthermore, within Experiment 1 (in which the participants saw only shame) shame was recognized more as shame than as embarrassment ( $M_{\text {shame }}=72$, $\left.S D=14 ; M_{\text {embarrassment }}=67, S D=15\right) t(65)=3.16, p=$ .002 . Within Experiment 2 this was vice versa for embarrassment $\left(M_{\text {embarrassment }}=70, S D=14 ; M_{\text {shame }}=66, S D=16\right)$ $t(61)=2.51, p=.02 .{ }^{1}$ Also, in all pictures a blush enhanced the impression that an emotion was displayed (both $p$ s $<.05$ ). A set of the pictures can be obtained from the first author on request.

Vignettes. We constructed 24 vignettes in such a way that the mishaps were typical antecedents of embarrassment and the trans- gressions were typical antecedents of shame (see Table 1; de Jong et al., 2003; Keltner \& Buswell, 1996). Before reading the vignettes, participants were instructed to imagine that they were the observer of the situation. In the situations, the observer never played a central role and was never a victim. All vignettes were used in a pilot study to verify that they were readily understandable and unambiguous in meaning, and were again tested on their content after the experiment. $T$ tests for both experiments showed that mishaps were perceived more as mishaps than as transgressions, and transgressions more as transgressions than as mishaps. That is, on two 100-point scales, transgression were $M=76$ $(S D=10)$ recognized as transgressions and $M=33(S D=17)$ as mishaps, $t(65)=16.26, p<.001$; mishaps were $M=71(S D=$ 12) recognized as mishap and $M=31(S D=15)$ as transgressions, $t(61)=16.29, p<.001$.

\section{Procedure and Measures}

For both experiments, the entire procedure was on a computer. During the experiment, participants first read the vignette and then the photograph was displayed above the vignette; after a 2-s interval, the vignette disappeared and four visual analogue scales (VASs) appeared on the screen below the picture (see Table 1 for the description of these VASs). Some VASs were similar for both experiments and some differed. This was because not all questions had the same relevance for each of the two experiments. For example, it seems illogical to ask about someone's trustworthiness after she falls over a vacuum cleaner cable or about someone's social skills after stealing underwear. Furthermore, blushing might especially enhance trustworthiness after a severe transgression (where trustworthiness is negatively affected) and vice versa enhance social skills after a mishap.

Participants were presented with 13 vignettes (the experiments started with 1 vignette to practice), which were all transgressions in the first experiment and all mishaps in the second experiment, but were coupled with one of four different facial expressions (blush vs. no blush on a neutral vs. emotional expression). To minimize the influence of carryover effects, there were four versions of each of the two experiments and participants were assigned randomly to one of these versions. In each of the four versions, the vignettes were randomly ordered. However, across these four versions each vignette was coupled with every possible expression. Thus, if a vignette was coupled with a photograph depicting a neutral expression without a blush in Version 1, the same vignette in Version 2 was coupled with one of the three remaining options (neutral with blush, emotion with or without blush). In each version, we used a particular model only once, to avoid carryover effects from previous emotional expressions for

\footnotetext{
${ }^{1}$ Note that the difference between shame and embarrassment is not so large. This is probably due to the fact that the use of the Dutch words for shame and embarrassment is slightly different from their English translation (although the emotional expressions in The Netherlands are similar to those described by Keltner \& Buswell, 1996). The word used for embarrassment in this study was gêne. However, in common parlance it is just as common to use the word schaamte to refer to this emotion; and that word is also used for shame. Thus, instead of having two separate words for shame and embarrassment, both expressions can be referred to as shame (see Castelfranchi \& Poggi, 1990, for a similar instance in Italian).
} 
Table 1

Description of Vignettes and the Visual Analogue Scales (VASs)

\begin{tabular}{|c|c|c|}
\hline \multicolumn{3}{|l|}{ Description } \\
\hline \multicolumn{3}{|l|}{ Vignettes } \\
\hline $\mathrm{T}$ & 1. Missing funeral because of party & 7. Damaging rear view of other car \\
\hline & 2. Driving away after car crash & 8. Jumping the queue at bakery \\
\hline & 3. Claiming too many traveling days & 9. Gossiping about someone's handicap \\
\hline & 4. Being intimate with nonspouse & 10. Using money lent for books to buy clothes \\
\hline & 5. Stealing underwear & 11. Speaking loud at a silent public place \\
\hline & 6. Using illegal notes during exam & 12. Appearing at pub after sick-report \\
\hline M & 1. Spilling coffee on someone & 7. Telling a boring yoke \\
\hline & 2. Appearing overdressed at informal party & 8. Getting skirt stuck in pantiesy after toilet \\
\hline & 3. Bumping into a rack full of wine glasses & 9. Driving bike into the bushes \\
\hline & 4. Upsetting a pile of cans in supermarket & 10. Damaging a rack full of perfume \\
\hline & 5. Falling over a vacuum cleaner cable & 11. Farting in an elevator \\
\hline & 6. Enthusiastically greeting unknown person & 12. Forgetting to lock toilet door \\
\hline \multicolumn{3}{|l|}{ VAS } \\
\hline 1. $(\mathrm{T} \& \mathrm{M})$ & How sympathetic do you find this person? & 0 (not at all sympathetic) to 100 (very sympathetic) \\
\hline 2. $(\mathrm{T})$ & How trustworthy do you find this person? & 0 (not at all trustworthy) to 100 (very trustworthy) \\
\hline 2. (M) & Do you find this person socially skillful? & $\begin{array}{l}0 \text { (not at all socially skillful) to } 100 \text { (very socially } \\
\text { skillful) }\end{array}$ \\
\hline 3. $(\mathrm{T} \& \mathrm{M})$ & What is your general impression? & 0 (negative) to 100 (positive) \\
\hline 4. (T) & To what extent do you have the impression that this person is ashamed? & 0 (not at all ashamed $)$ to 100 (very ashamed $)$ \\
\hline 4. (M) & To what extent do you have the impression that this person is embarrassed? & 0 (not at all embarrassed) to 100 (very embarrassed) \\
\hline
\end{tabular}

Note. $\mathrm{T}=$ transgression; $\mathrm{M}=$ mishap.

this particular model. The models were assigned randomly to 1 of the 12 vignettes.

\section{Data Reduction}

We calculated the mean score of the first three VASs, containing the judgment of the actor, for every possible expression (neutral, neutral blush, emotion, emotion blush). To see if this could be done reliably, we examined Cronbach's alphas for the four types of expressions in the two experiments; all alphas were sufficiently large $($ all $>.90)$.

\section{Results}

To test the effect of displaying a blush as a function of a shameful/embarrassed or neutral expression, data were subjected to a two response (blush vs. no blush) by two emotion (emotion vs. neutral) repeated measure analysis. In addition, we performed a paired $t$ test to test the relative efficacy of displaying the blush on a neutral face versus the expression of shame/embarrassment without a blush specifically; and $t$ tests to test the effect of blushing for each expression (neutral and emotion). Furthermore, we performed a multilevel-repeated measures analysis to examine if the intensity rating of the emotion mediates the appeasing effect of the blush. For both experiments, Table 2 displays the relevant means and standard deviations as well as the results from these $t$ tests.

\section{Experiment 1: Distinct Effect of Displaying a Blush After a Transgression}

Judgment of the actor. There was a main effect of the blush response, $F(1,65)=12.87, p=.001, \eta_{p}^{2}=0.17$; the actor was judged more positive when she blushed than when she did not blush. In addition, there was a main effect of emotion, $F(1,65)=$
12.83, $p=.001, \eta_{\mathrm{p}}^{2}=0.17$; the actor was judged more positive when she displayed shame than when she displayed a neutral face. There was no response by emotion interaction, $F(1,65)<1$.

Shame. There was a main effect of the blush response, $F(1$, $65)=27.29, p<.001, \eta_{\mathrm{p}}^{2}=0.30$. This effect indicates that more shame was attributed to the actor when she blushed, than when she did not blush. Also, there was a main effect of emotion, $F(1,65)=$ 91.13, $p<.001, \eta_{\mathrm{p}}^{2}=0.58$; the actor was judged as being more ashamed when she displayed shame than when she displayed a neutral face. There was no response by emotion interaction, $F(1,65)<1$.

The blush versus shame. The $t$ test showed that the evaluative judgment of the actor was the same for the neutral-blush display and the shame display without a blush, $t(65)<1$. The intensity rating of shame was larger for the shame display without a blush than for the neutral-blush display, $t(65)=5.09, p<.001$ (see Table 2).

Judgment mediated by shame. ${ }^{2}$ To examine if the rated intensity of shame mediates the appeasing effect of the blush we conducted a multilevel, repeated measures analysis with three levels (Blush within Emotion within Participant). The analyses showed that the intensity of shame indeed mediates the judgment of the participant. The regression equation (with the standard deviations of the estimated means) appeared to be as follows: judgment $=17.17(S D=1.78)$ intercept $+0.95(S D=1.54)$ blush $+0.30(S D=0.03)$ shame.

\footnotetext{
${ }^{2}$ Because we measured both response (blush vs. no blush) as well as emotion (shame/embarrassment vs. neutral) within participants, it was necessary to use a multilevel regression method to test if the effect of blushing on judgment is mediated by the perceived intensity of shame/ embarrassment. Furthermore, note that blush is an independent dummyvariable and shame/embarrassment the rating of the participant. More details of the analyses can be obtained from the first author.
} 
Table 2

Means and Standard Deviations of the Dependent Variables

\begin{tabular}{|c|c|c|c|c|c|}
\hline Variable & No blush & Blush & & No blush & Blush \\
\hline Transgression experiment & \multicolumn{2}{|c|}{ Neutral } & \multicolumn{3}{|c|}{ Shame } \\
\hline Judgment of the actor ${ }^{\mathrm{a}}$ & $27(13)$ & $<31(14)$ & $=$ & $32(13)$ & $<36(15)$ \\
\hline Shame & $29(15)$ & $<38(18)$ & $<$ & $53(21)$ & $<62(19)$ \\
\hline Mishap experiment & \multicolumn{2}{|c|}{ Neutral } & \multicolumn{3}{|c|}{ Embarrassment } \\
\hline Judgment of the actor ${ }^{\mathrm{a}}$ & $54(12)$ & $<57(13)$ & $<$ & $62(14)$ & $={ }^{\mathrm{b}} 64(11)$ \\
\hline Embarrassment & $54(17)$ & $<65(18)$ & $=$ & $68(16)$ & $<76(16)$ \\
\hline
\end{tabular}

Note. Standard deviations are in parentheses. The "less than" $\operatorname{sign}(<)=$ difference between the variables is significant at the $p<.05$ level. The "equal" sign $(=)=$ no significant difference between the variables.

${ }^{a}$ The variable refers to a composite (see the Data Reduction section). ${ }^{\mathrm{b}}$ Note that the absence of a significant difference between blush and no blush should be interpreted with care because the analyses revealed a main effect of the blush response but no interaction between emotion and blush.

\section{Experiment 2: Distinct Effect of Displaying a Blush After a Mishap}

Judgment of the actor. Analyses showed a main effect of the blush response, $F(1,61)=5.45, p=.023, \eta_{\mathrm{p}}^{2}=0.08$. Participants judged the actor more positive when she blushed than when she did not blush. There was a main effect of emotion, $F(1,61)=$ $37.32, p<.001, \eta_{\mathrm{p}}^{2}=0.38$; an actor who displayed embarrassment was judged more positive than an actor who displayed a neutral face. The response by emotion interaction was not significant, $F(1$, $61)<1$. Although the absence of an emotion by blush interaction indicates that the influence of the blush was similar for the neutral and embarrassment displays, paired comparisons showed that for the embarrassment display the influence of the blush did not reach significance (see Table 2).

Embarrassment. There was a main effect of the blush response, $F(1,61)=30.79, p<.001, \eta_{\mathrm{p}}^{2}=0.34$; more embarrassment was attributed to the actor when she blushed than when she did not blush. In addition, there was a main effect of emotion, $F(1$, $61)=34.29, p<.001, \eta_{\mathrm{p}}^{2}=0.36$; the model was judged as being more embarrassed when she displayed embarrassment than when she displayed a neutral face. There was no significant response by emotion interaction, $F(1,126)=2.64, p=.109$.

The blush versus embarrassment. The $t$ test showed that the participants judged the actor more positive when she displayed embarrassment than when she displayed a neutral face with a blush, $t(61)=3.00, p=.004$. The intensity rating of embarrassment did not differ between the embarrassment display and the neutral-blush display, $t(61)=1.03, p=.306$.

Judgment mediated by embarrassment. ${ }^{3}$ A multilevelrepeated measures analysis with three levels (Blush within Emotion within Participant) showed that the intensity of embarrassment mediates the judgment of the participant. The regression equation (with the standard deviations of the estimated means) is as follows: judgment $=37.88(S D=2.74)$ intercept $-0.490(S D=1.53)$ blush $+0.33(S D=0.04)$ Embarrassment.

\section{Discussion}

The results showed that blushing has remedial properties. In the context of transgressions as well as in the context of mishaps, displaying a blush on a neutral face positively affected the observers' judgments. Specifically in the context of transgressions, blushing also significantly improved the observers' judgments when the blush was displayed on top of shame. This pattern of findings indicates that blushing indeed has signal value in addition to other facial expressions, and is consistent with the view that blushing might contribute to the prevention of social exclusion after a transgression has been committed (e.g., Castelfranchi \& Poggi, 1990; de Jong, 1999; Leary \& Meadows, 1991). Furthermore, for all displays a blush intensified the impression that the actor felt ashamed or embarrassed.

The results of the mediation analyses suggest that blushing might succeed in affecting the judgment via the enhancement of the perceived intensity of the actor's shame or embarrassment. Thus, blushing signals that one experiences more of the emotion, which subsequently gives rise to a more positive judgment. Because the available range of expressing shame/embarrassment via contraction of the relevant facial musculature is restricted, the blush might have useful complementary remedial value, especially when people already reached a full-blown (muscular) expression of shame/embarrassment. Furthermore, blushing might have complementary value by attesting to the apparent sincerity that one is ashamed and/or embarrassed. That is, because it is impossible to control the blush intentionally, blushing might signal that one is truly ashamed and not faking the expressions (Frank, 1988, chap. 5). In support of its benefit, the remedial effects of the facial expression of shame increased significantly when a blush was added to the actor's shameful face.

We additionally examined the relative efficacy of a blush visà-vis the other facial expressions of embarrassment or shame as a remedial gesture. Following a clear-cut transgression, a neutral but blushing face was rated as less ashamed than a facial expression of shame without a blush. However, merely displaying a blush elicited similar remedial effects as showing the facial expression of shame without a blush. The sincerity of the signal might be an explanation for this remedial effect of blushing (cf. Frank, 1988). A sincere acknowledgment that one is aware of the wrongdoing might decrease the expectancy that the blushing individual will defect again (Gold \& Weiner, 2000). Clearly, more research is necessary to reach more firm conclusions about these alleged effects of blushing.

Some comments are in order with regard to the present study. First, the generalizability of the present study may be restricted; the present study tested the communicative value of blushing in clear-cut predicaments. Because the communicative value of blushing depends greatly on the context (de Jong, et al., 2003, 2002), further research should test the communicative properties of the blush in different contexts. In addition, it is conceivable that apart from its desirable remedial properties, blushing may also have less desirable consequences such as eliciting the impression that the blusher is immature or incompetent (cf. Semin \& Manstead, 1982). Furthermore, although blushing is universal and occurs in all races and sexes, the experience of the blush has been shown to depend on complexion color and sex (Drummond \& Lim, 2000; Simon \& Shields, 1996). It would be interesting to see if the signal value of the blush also depends on these characteristics. It is

\footnotetext{
${ }^{3}$ See footnote 2 .
} 
for example, conceivable that the influence of displaying a blush differs between men and women (Hess, Adams, \& Kleck, 2004; Keltner, 1995). Now that the present study, which used only White women, showed that blushing has communicative effects, it would be interesting to replicate the study with male models and models with different skin colors.

Second, it should be acknowledged that the present study relied on vignettes rather than actual interactions. Such an approach relies on the participants' ability to accurately report how they would judge a person in real life, and one may question whether individuals are indeed (always) able to do so (e.g., Parkinson \& Manstead, 1993). However, in the present study the participants were not asked to imagine what the actor looked like; instead, they actually saw the people they had to judge, which reflects more lifelike situations. In addition, although most participants indicated that they had not explicitly noticed that the study was about blushing (when we asked, just two participants mentioned that they suspected that the study investigated blushing), the blush nevertheless influenced their ratings.

To conclude, this study is the first to show that blushing has signaling and remedial value, both on a neutral as well as a shameful expression. Although most people consider blushing to be an undesirable response (Shields et al., 1990), our results showed that in the context of transgressions and mishaps, blushing is a helpful bodily signal with face-saving properties. It seems therefore unwise to hide the blush or to try not to blush in these types of contexts, or even to remove the ability to blush altogether by means of the surgical cutting through of the sympathetic nerve (e.g., Dijk \& de Jong, 2006).

\section{References}

Babcock, M. K., \& Sabini, J. (1990). On differentiating embarrassment from shame. European Journal of Social Psychology, 20, 151-169.

Buss, A. H., (1980). Self-consiousness and social anxiety. San Francisco: Freeman.

Castelfranchi, C., \& Poggi, I. (1990). Blushing as a discourse: Was Darwin wrong? In W. R. Crozier (Ed.), Shyness and embarrassment: Perspectives from social psychology (pp. 230-251). Cambridge, England: Cambridge University Press.

Crozier, W. R. (2006). Blushing and the social emotions: The self unmasked. New York: Palgrave MacMillan.

Cutlip, W. D., \& Leary, M. R. (1993). Anatomic and physiological bases of social blushing: Speculations from neurology and psychology. Behavioral Neurology, 6, 181-185.

Darwin, C. (1989). The expression of the emotions in man and animals. New York: New York University Press. (Original work published in 1872)

de Jong, P. J. (1999). Communicative and remedial effects of social blushing. Journal of Nonverbal Behavior, 23, 197-218.

de Jong, P. J., Peters, M. L., \& De Cremer, D. (2003). Blushing may signify guilt: Revealing effects of blushing in ambiguous social situations. Motivation and Emotion, 27, 225-249.

de Jong, P. J., Peters, M. L., De Cremer, D., \& Vranken, C. (2002).
Blushing after a moral transgression in a prisoner's dilemma game: Appeasing or revealing? European Journal of Social Psychology, 32, 727-644.

Dijk, C., \& de Jong, P. J. (2006). Surgical treatment for blushing. The Lancet, 367, 2059.

Drummond, P. D., \& Lance, J. W. (1987). Facial flushing and sweating is mediated by the sympathetic nervous system. Brain, 110, 793-803.

Drummond, P. D., Lim, H. K. (2000). The significance of blushing for fairand dark-skinned people. Personality and Individual Differences, 29, 1123-1132.

Frank, R. H. (1988). Passions within reason: The strategic role of the emotions. New York: Norton.

Frijda, N. (1986). The emotions. Cambridge, England: Cambridge University Press.

Gold, G. J., \& Weiner, B. (2000). Remorse, confession, group identity, and expectancies about repeating a transgression. Basic and Applied Social Psychology, 22, 291-300.

Hess, U., Adams Jr., R. B., \& Kleck, R. E. (2004). Facial appearance, gender, and emotion expression. Emotion, 4, 378-388.

Keltner, D. (1995). Signs of appeasement: Evidence for the distinct displays of embarrassment, amusement, and shame. Journal of Personality and Social Psychology, 68, 441-454.

Keltner, D., \& Buswell, B. N. (1996). Evidence for the distinctness of embarrassment, shame and guilt: A study of recalled antecedents and facial expressions of emotion. Cognition and Emotion, 10, 155-171.

Keltner, D., Young, R. C., \& Buswell, B. N. (1997). Appeasement in human emotion, social practice, and personality. Aggressive Behavior, $23,359-374$

Leary, M. R., \& Meadows, S. (1991). Predictors, elicitors, and concomitants of social blushing. Journal of Personality and Social Psychology, $60,254-262$

Mellander, S., Andersson, P., Afzelius, L., \& Hellstrand, P. (1982). Neural beta-adrenergic dilation of the facial vein in man: Possible mechanism in emotional blushing. Acta Physiologica Scandinavia, 114, 393-399.

Miller, R. S., \& Tangney, J. P. (1994). Differentiating embarrassment and shame. Journal of Social and Clinical Psychology, 13, 273-287.

Modigliani, A. (1968). Embarrassment and embarrassability. Sociometry, $31,313-326$.

Parkinson, B., \& Manstead, A. S. R. (1993). Making sense of emotions in stories and social life. Cognition and Emotion, 7, 295-323.

Semin, G. R., \& Manstead, A. S. R. (1982). The social implications of embarrassment displays and restitution behavior. European Journal of Social Psychology, 12, 367-377.

Shields, S. A., Mallory, M. E., \& Simon, A. (1990). The experience and symptoms of blushing as a function of age and reported frequency of blushing. Journal of Nonverbal Behavior, 14, 171-187.

Simon, A., \& Shields, S. A. (1996). Does complexion color affect the experience of blushing? Journal of Social Behavior and Personality, 11, $177-188$.

Tangney, J. P., Miller, R. S., Flicker, L., \& Barlow, D. H. (1996). Are shame, guilt, and embarrassment distinct emotions? Journal of Personality and Social Psychology, 70, 1256-1269.

Received July 16, 2007

Revision received September 15, 2008 Accepted December 10, 2008 